\title{
Nutritional state modulates growth hormone-stimulated lipolysis
}

Heather E. Bergan ${ }^{1}$, Jeffrey D. Kittilson, and Mark A. Sheridan ${ }^{2 *}$

12 Running head: Nutritional state modulates GH-stimulated lipolysis

14 Address correspondence and send proofs to:

* Corresponding author. Tel.:+1 806 742-2781; fax +1 8067424038.

E-mail address: mark.sheridan@ttu.edu (M.A. Sheridan)

${ }^{1}$ Present address: School of Natural Resources, University of Nebraska, Lincoln, Nebraska 68583

29 USA

$30 \quad{ }^{2}$ Present address: Department of Biological Sciences, Texas Tech University, Lubbock TX 


\section{ABSTRACT}

34 Growth hormone $(\mathrm{GH})$ regulates several processes in vertebrates, including two metabolically

35 disparate processes: promotion of growth, an anabolic action, and mobilization of stored lipid, a

36 catabolic action. In this study, we used hepatocytes isolated from continuously fed and long-term

37 (4 week) fasted rainbow trout (Oncorhynchus mykiss) as a model to investigate the mechanistic

38 basis of the anabolic and catabolic actions of GH. Our hypothesis was that nutritional state

39 modulates the lipolytic responsiveness of cells by adjusting the signal transduction pathways to

40 which GH links. GH stimulated lipolysis as measured by increased glycerol release in both a

41 time- and concentration-related manner from cells of fasted fish but not from cells of fed fish.

42 Expression of mRNAs that encode the lipolytic enzyme hormone-sensitive lipase (HSL), HSL1

43 and HSL2, also was stimulated by GH in cells from fasted fish and not in cells from fed fish.

44 Activation of the signaling pathways that mediate $\mathrm{GH}$ action also was studied. In cells from fed

45 fish, GH activated the JAK-STAT, PI3K-Akt, and ERK pathways, whereas in cells from fasted

46 fish, GH activated the PLC/PKC and ERK pathways. In hepatocytes from fasted fish, blockade

47 of PLC/PKC and of the ERK pathway inhibited GH-stimulated lipolysis and GH-stimulated HSL

48 mRNA expression, whereas blockade of JAK-STAT or of the PI3K-Akt pathway had no effect

49 on lipolysis or HSL expression stimulated by GH. These results indicate that during fasting GH

50 activates the PLC/PKC and ERK pathways resulting in lipolysis but during periods of feeding

$51 \mathrm{GH}$ activates a different complement of signal elements that do not promote lipolysis. These

52 findings suggest that the responsiveness of cells to GH depends on the signal pathways to which

$53 \mathrm{GH}$ links and helps resolve the growth-promoting and lipid catabolic actions of GH.

55 Keywords: Growth hormone, lipolysis, signal transduction, rainbow trout (Oncorhynchus mykiss) 


\section{Introduction}

Growth hormone $(\mathrm{GH})$ coordinates numerous physiological processes in vertebrates,

61 including various aspects of feeding, growth, metabolism, osmoregulation, immune function, and

62 behavior (Bjornsson et al., 2004; Moller and Jorgensen, 2009; Norrelund, 2005; Reindl and

63 Sheridan, 2012). The growth-promoting actions of GH occur during periods of feeding and are

64 primarily mediated through insulin-like growth factor-1 (IGF-1) produced chiefly in the liver, a

65 mode of action that is highly conserved from fish to mammals (Butler and LeRoith, 2001;

66 Reinecke et al., 2005; Wood et al., 2005). GH stimulates hepatic IGF-1 synthesis and secretion

67 by activating three cell signaling pathways: JAK-STAT, PI3K-Akt, and ERK (Reindl et al.,

68 2011). Fish, which are particularly good models for the study of growth because most species

69 have the capacity to grow throughout their life (i.e., indeterminate growth), display increases in

70 body weight and body length when continuously feed, both of which are accelerated by GH

71 treatment (cf. Norbeck et al., 2007; Biga and Meyer, 2009). Interestingly, some species of fish

72 display a steepened growth trajectory (i.e., compensatory growth) compared to continuously fed

73 animals upon refeeding following a bout of food deprivation that has been attributed to, at least

74 in part, a sensitized GH-IGF system (Won and Borski, 2013).

75 During periods when food is not available, energy is diverted away from growth to

76 sustain metabolic processes. In rainbow trout, for example, animals cease growing compared to

77 their fed counter parts and mobilize stored lipid and carbohydrate and activate gluconeogenesis;

78 with prolonged fasting such mobilization is reflected in animals as reduced condition and

79 reduced body weight (Norbeck et al., 2007; Sheridan and Mommsen, 1991). Accompanying the 
catabolic shift is an alteration in the endocrine profile, including depression of plasma levels of

81 insulin and IGF-1 (Caruso and Sheridan, 2011; Norbeck et al., 2007; Sheridan and Mommsen,

82 1991); however, despite cessation of growth, plasma levels of GH increase, a pattern that is seen

83 in fish as well as other vertebrates (Gomez-Requeni et al., 2005; Norbeck et al., 2007). This

84 rather enigmatic finding most likely underlies the mobilization of lipid observed during fasting.

85 Evidence that GH stimulated lipid breakdown in fish was first shown in liver and adipose tissue

86 of coho salmon in vivo (Sheridan, 1986). GH was subsequently shown to directly stimulate

87 lipolysis in liver of rainbow trout (O’Connor et al., 1993) and in adipose tissue of seabream

88 (Albalat et al., 2005) in vitro. Using rainbow trout hepatocytes as a model, we recently showed

89 for the first time in any species that GH promotes lipolysis by activating (via phosphorylation)

90 the lipolytic enzyme that hydrolyzes stored lipid (e.g., triacylglycerol), hormone-sensitive lipase

91 (HSL), and by stimulating the expression of HSL-encoding mRNAs (Bergan et al., 2013).

92 Despite our understanding of the role of GH in growth promotion and lipid catabolism,

93 the mechanisms that enable the activation of such metabolically disparate processes are

94 unknown. In this study, we used hepatocytes isolated from continuously fed and long-term (4

95 week) fasted rainbow trout (Oncorhynchus mykiss) as a model to investigate the mechanistic

96 basis of the anabolic and catabolic actions of $\mathrm{GH}$. Our hypothesis was that nutritional state

97 modulates the lipolytic responsiveness of cells by adjusting the signal transduction pathways to

98 which GH links. The rationale for this work extends from our previous observations in rainbow

99 trout that selected signaling pathways are activated during periods of feeding (e.g., JAK-STAT,

100 PI3K-Akt), whereas a different complement of signaling pathways are activated during periods

101 of fasting (e.g., ERK, PKC) (Bergan et al., 2012) and that hepatic lipolysis results from GH

102 activation of PLC/PKC and ERK (Bergan et al., 2013). 


\section{Materials and Methods}

\section{2.1. Materials}

All chemicals and reagents were purchased from Sigma (St. Louis, MO, USA) unless

106 stated otherwise. Antibodies for the phospho-specific and total (recognizing both

107 phosphorylated and nonphosphorylated protein) forms of Akt, ERK1/2, JAK2, PKC $\alpha / \beta$ II, and

108 STAT5, horseradish peroxidase (HRP)-linked anti-rabbit IgG antibody, biotinylated molecular

109 weight marker, anti-biotin-HRP antibody, mitogen-activated protein kinase kinase 1/2 (MEK1/2)

110 inhibitor U0126 (MEK1 and 2 are directly responsible for the activation of ERK), PI3K inhibitor

111 LY294002 [PI3K produces phosphatidylinositol phosphates that are critical for activation of Akt

112 by phosphoinostide-dependent kinase 1 (PDK1)], and cell lysis buffer were all obtained from

113 Cell Signaling Technology (Beverly, MA, USA). The JAK2 inhibitor, 1,2,3,4,5,6-

114 hexabromocyclohexane (Hex), the broad spectrum protein kinase $\mathrm{C}(\mathrm{PKC})$ inhibitor,

115 chelerythrine chloride, and the broad spectrum phospholipase C inhibitor, U73122, were

116 obtained from EMD Chemicals (Gibbstown, NJ, USA). Molecular weight markers were

117 purchased from Bio-Rad Laboratories (Hercules, CA, USA). Salmonid GH was generously

118 provided by Prof. Akiyoshi Takahashi and Dr. Shunsuke Moriyama (Kitasato University, Japan).

\subsection{Experimental animals and conditions}

121 Juvenile rainbow trout of both sexes ( $c$. 1 year of age) were obtained from Dakota Trout

122 Ranch (Carrington, ND). The animals were transported to North Dakota State University, where

123 they were maintained in well-aerated, 800-L circular tanks supplied with recirculated (10\%

124 make-up volume per day) dechlorinated municipal water at $14^{\circ} \mathrm{C}$ under a $12: 12$ hour light:dark

125 photoperiod. Fish were acclimated to laboratory conditions for at least 4 weeks prior to 
126 experimentation and were routinely fed twice daily to satiety with AquaMax Grower (PMI

127 Nutrition International, Brentwood, MO, USA) semi-floating trout grower. All procedures were

128 performed in accordance with the Guide for the Care and Use of Laboratory Animals, $8^{\text {th }}$ edition

129 (National Research Council, Washington, DC) and were approved by the North Dakota State

130 University Institutional Animal Care and Use Committee.

$131 \quad$ For experiments, fish were either fed or fasted continuously for 4 weeks; for the fed 132 group animals were sampled $2 \mathrm{~h}$ after feeding. Animals were anesthetized by immersion in $1330.05 \%(\mathrm{v} / \mathrm{v})$ 2-phenoxyethanol and euthanized by transection of the spinal cord. Hepatocytes 134 were isolated by in situ perfusion (Mommsen et al., 1994). The isolated cells were incubated in 135 recovery medium [in mM: $137.8 \mathrm{NaCl}, 5.4 \mathrm{KCl}, 0.80 \mathrm{MgSO}_{4}, 0.4 \mathrm{KH}_{2} \mathrm{PO}_{4}, 0.34 \mathrm{Na}_{2} \mathrm{HPO}_{4}, 4.2$ $136 \mathrm{NaHCO}_{3}$, and 10 HEPES, 0.65 glucose, $\mathrm{pH}$ 7.6, with 2\% defatted BSA, $2 \mathrm{ml}$ MEM amino acid $137 \operatorname{mix}(50 \mathrm{X}) / 100 \mathrm{ml}$, and $1 \mathrm{ml}$ nonessential amino acid mix $(100 \mathrm{X}) / 100 \mathrm{ml}]$ for $2 \mathrm{~h}$ at $14^{\circ} \mathrm{C}$ with 138 gyratory shaking (100 rpm under $\left.100 \% \mathrm{O}_{2}\right)$. The viability of the cells was assessed by trypan 139 blue dye exclusion and ranged between $93-97 \%$ for all experiments. After the recovery period, 140 hepatocytes were collected by centrifugation (550 $\mathrm{g}$ for 8-10 $\mathrm{min}$ ) and resuspended in incubation 141 media (recovery media with $1.5 \mathrm{mM} \mathrm{CaCl}_{2}$ ) to a final concentration of $6-8 \times 10^{6}$ cells/ml, and 142 aliquoted into 24 -well plates $\left(6-8 \times 10^{6}\right.$ cells/well). Cells were incubated in medium alone 143 (control) or in medium with GH as specified in the figure legends under the same conditions as 144 those used for recovery $\left(14^{\circ} \mathrm{C}\right.$ with gyratory shaking at $100 \mathrm{rpm}$ under $\left.100 \% \mathrm{O}_{2}\right)$. In combination 145 experiments involving pathway inhibition, inhibitors were added $2 \mathrm{~h}$ prior to GH treatment at 146 concentrations specifically recommended by the manufacturer and/or used by us previously 147 (Reindl et al., 2011) as follows: $20 \mu \mathrm{M}$ LY294002, $10 \mu \mathrm{M} \mathrm{U} 0126,50 \mu \mathrm{M}$ Hex, $10 \mu \mathrm{M}$ 
148 chelerythrine chloride, and $10 \mu \mathrm{M}$ U73122. In all cases, cells in replicate treatments came from 149 different fish

After treatment, cells were pelleted (1,000 x g for $4 \mathrm{~min})$ and the supernatant medium

151 was removed. Cells were washed with $0.5 \mathrm{ml}$ phosphate-buffered saline. Cell pellets and 152 medium samples were immediately frozen on dry ice then stored at $-80^{\circ} \mathrm{C}$ until further analysis.

\subsection{Hormone-sensitive lipase mRNA expression}

Total RNA was extracted using TRI-Reagent ${ }^{\circledR}$ (Molecular Research Center, Inc.,

156 Cincinnati, OH, USA) as specified by the manufacturer's protocol. Each RNA pellet was

157 redissolved in 35-200 $\mu$ l RNase-free deionized water and quantified by NanoDrop1000

158 spectrophotometry $\left(\mathrm{A}_{260}\right)$ (Thermo Scientific, West Palm Beach, FL, USA). RNA samples were

159 then stored at $-80^{\circ} \mathrm{C}$ until further analysis. mRNA was reverse transcribed in $5 \mu$ reactions using

$160150 \mathrm{ng}$ total RNA and AffinityScript QPCR cDNA Synthesis kit reagents (Master Mix, random

161 primers, oligo-dT primers, and reverse transcriptase with block) according to the manufacturer's

162 protocol (Stratagene, La Jolla, CA, USA). Reactions without reverse transcriptase were included

163 as negative controls to exclude the possibility of contamination from genomic DNA; no

164 amplification was detected in negative controls.

165 Rainbow trout possess two HSL-encoding mRNAs, HSL1 and HSL2, and steady-state

166 levels of each were determined by quantitative real-time PCR as described previously (Kittilson

167 et al., 2011). Briefly, real-time reactions were carried out for samples, standards, and no-

168 template controls in multiplex reactions with HSL1 or HSL2 and $\beta$-actin. Reactions contained 2

$169 \mu \mathrm{l}$ cDNA from the reverse transcription reactions, $5 \mu$ B Brilliant@ II QPCR Master Mix

170 (Stratagene), $1 \mu \mathrm{l}$ of each $150 \mathrm{nM}$ gene-specific probes, $0.5 \mu \mathrm{l}$ of $600 \mathrm{nM}$ gene-specific forward 
171 and reverse primers, and $0.15 \mu \mathrm{l}$ reference dye (Stratagene, Agilent Technologies). Cycling

172 parameters were set as follows: $95^{\circ} \mathrm{C}$ for $10 \mathrm{~min}$ and 45 cycles of $95^{\circ} \mathrm{C}$ for $30 \mathrm{~s}$ and $58^{\circ} \mathrm{C}$ for 1

173 min. Cross reaction was assessed by substituting alternate primer/probe sets in assays for each

174 standard; no amplification was observed under these conditions. Sample copy number was

175 calculated from the threshold cycle number $\left(\mathrm{C}_{\mathrm{T}}\right)$ and relating $\mathrm{C}_{\mathrm{T}}$ to a gene-specific standard

176 curve, followed by normalization to $\beta$-actin.

177

178 2.4. Western blot analysis

179 Cells were homogenized in $300 \mu 1$ 1x cell lysis buffer (Cell Signaling Technology,

180 Beverly, MA) with 1mM PMSF, 1x protease inhibitor (Calbiochem, San Diego, CA, USA), and

181 1x phosphotase inhibitor (G-Biosciences, St. Louis, MO, USA). The homogenate was incubated 182 on ice for 5 minutes then centrifuged at $16,000 \mathrm{xg}$ for $10 \mathrm{~min}$ at $4^{\circ} \mathrm{C}$. The protein concentration

183 of the supernatant was determined by the Bio-Rad (Hercules, CA, USA) dye-binding method for 184 microplates. Protein $(50 \mu \mathrm{g})$ was separated by SDS-PAGE (7.5\% running gel) and transferred to $185 \quad 0.45 \mu \mathrm{m}$ nitrocellulose (Bio-Rad Laboratories) for western analysis as previously described 186 (Reindl et al., 2011; Bergan et al., 2012). Membranes were washed and visualized with 187 chemiluminescence according to the manufacturer's instructions (GE Healthcare,

188 Buckinghamshire, UK); chemiluminescence was detected directly and the bands quantified with 189 a FluorChem FC2 imager (Alpha Innotech Corp, San Leandro, CA, USA). The abundance of 190 phosphorylated ERK 1/2, Akt, JAK2, STAT5, and PKC $\alpha / \beta$ II was normalized to total ERK 1/2, 191 Akt, JAK2, STAT5, and $\beta$-actin, respectively. The use of these commercial antisera to detect 192 signal elements in rainbow trout was previously validated (Bergan et al., 2012; Reindl et al., 193 2011). 
Medium samples were deproteinated $\left(65^{\circ} \mathrm{C}\right.$ for $\left.10 \mathrm{~min}\right)$, then centrifuged $(16,000 \mathrm{x} \mathrm{g}$ for

$19610 \mathrm{~min}$ at room temperature). An aliquot of the supernatant was added to a microplate well

197 containing buffer $\mathrm{A}\left(0.205 \mathrm{M} \mathrm{K}_{2} \mathrm{CO}_{3}, 0.205 \mathrm{M} \mathrm{KHCO}_{3}, \mathrm{pH} 10.0,0.65 \mathrm{M}\left(\mathrm{NH}_{4}\right)_{2} \mathrm{SO}_{4}\right), \mathrm{NAD}^{+}$

198 (10 mM in Buffer A), and glycerol dehydrogenase [7 units/ml in buffer B (4.76 $\mathrm{mM} \mathrm{KH}_{2} \mathrm{PO}_{4}$,

$\left.1994.76 \mathrm{mM} \mathrm{K}_{2} \mathrm{HPO}_{4}, \mathrm{pH} 7.6,1.4 \mu \mathrm{M} \mathrm{MnCl}_{2}, 0.9 \mu \mathrm{M}\left(\mathrm{NH}_{4}\right)_{2} \mathrm{SO}_{4}\right)$ ], in a 4:2:1:1 ratio, respectively,

200 in a total volume of $200 \mathrm{ul}$. Mixtures were incubated at $25^{\circ} \mathrm{C}$ for $1 \mathrm{~h}$, after which time the

201 absorbency was read at $340 \mathrm{~nm}$.

202

203 2.6. Data analysis

204 Statistical differences were estimated by one-way or two-way ANOVA, as appropriate.

205 In all cases, main effects were significant, and no significant interactions were observed between

206 main effects in two-way ANOVAs. Pairwise comparison of simple effects was assessed by

207 Duncan's multiple range test; statistical notations on the faces of the figures reflect such

208 comparisons. A probability level of 0.05 was used to indicate significance. All statistics were

209 performed using SigmaStat v. 1.0 (SPSS, Chicago, IL, USA).

210

\section{3. Results}

212 3.1. GH stimulates lipolysis in hepatocytes from fasted fish but not from fed fish

213 The lipolysis of stored lipids by HSL results in the release of glycerol into culture

214 medium from hepatocytes incubated in vitro. The effects of GH on the time course of glycerol

215 release from hepatocytes isolated from 4-week fasted fish and from continuously fed fish are

216 shown Fig. 1A. The initial release of glycerol from cells of fasted fish $\left(12 \pm 2 \mu \mathrm{M} / 10^{6}\right.$ cells $)$ was 
217 slightly but not significantly higher than that from cells of fed fish $\left(10 \pm 1 \mu \mathrm{M} / 10^{6}\right.$ cells $)$. GH

218 rapidly stimulated glycerol release from hepatocytes from fasted fish, and within $3 \mathrm{~h}$ of treatment

219 glycerol levels increased significantly above initial levels. The rate of GH-stimulated glycerol

220 release from hepatocytes from fasted fish slowed over time but continued to increase for up to 24

221 hours. By contrast, GH had no effect on glycerol release from hepatocytes isolated from fish fed

222 continuously at any time period measured. The effects of GH concentration on glycerol release

223 from hepatocytes from 4-week fasted and from continuously fed fish also were determined (Fig.

224 1B). Similar to the results of the time course experiment, basal glycerol release from cells from

225 fasted fish $\left(12 \pm 2.5 \mu \mathrm{M} / 10^{6}\right.$ cells $)$ was slightly but not significantly higher than that from cells

226 from fed fish $\left(9.7 \pm 1.0 \mu \mathrm{M} / 10^{6}\right.$ cells $)$. GH stimulated glycerol release from hepatocytes from

227 fasted fish in a concentration-related manner. Glycerol release from fasted fish was stimulated

228 significantly above basal levels at a concentration of $\mathrm{GH}$ as low as $1 \mathrm{ng} / \mathrm{ml}$. GH continued to

229 stimulate glycerol release from hepatocytes from fasted fish at progressively higher

230 concentrations, with maximum release observed at $100-1000 \mathrm{ng} / \mathrm{ml}$. GH had no effect on

231 glycerol release from hepatocytes from continuously fed fish at any concentration of hormone

232 tested. Taken together, these results indicate that GH stimulates lipolysis as measured by

233 glycerol release from hepatocytes of fasted fish but not from cells of continuously fed fish.

234 We next investigated the influence of GH on $H S L$ mRNA expression in hepatocytes

235 isolated from 4-week fasted fish and from fish fed continuously. Rainbow trout possess two

236 HSL-encoding mRNAs, HSL1 and HSL2 (Kittilson et al., 2011); both mRNA forms were

237 detected in all samples and treatments of hepatocytes. In hepatocytes from fasted fish, GH

238 stimulated the expression of both HSL-encoding mRNAs in a time-dependent matter (Fig. 2A).

239 A significantly increase in the expression $H S L 1$ and $H S L 2$ mRNAs in cells from fasted fish was 
observed after $3 \mathrm{~h}$ of $\mathrm{GH}$ treatment. Maximum stimulation of HSL mRNA expression in cells

241 from fasted fish occurred after $12 \mathrm{~h}$ of GH treatment, increasing $244 \%$ and $277 \%$ for $H S L 1$ and

242 HSL2, respectively; after 24 h of GH treatment, mRNA expression decreased significantly from

243 peak values but not to levels observed in controls or in cells from fed fish. HSL1 and HSL2

244 mRNAs were differentially expressed only after $3 \mathrm{~h}$ of GH treatment in hepatocytes from fasted

245 fish, with HSL2 mRNA being expressed to a greater extent than HSL1. GH had no effect on $H S L$

246 mRNA expression in hepatocytes isolated from continuously fed fish at any time period

247 measured. The effects of GH concentration on HSL mRNA expression in hepatocytes from 4-

248 week fasted and from continuously fed fish also were determined (Fig. 2B). In hepatocytes from

249 fasted fish, GH stimulated $H S L$ mRNA expression in a dose-related manner. The expression of

250 HSL2 mRNA was significantly stimulated over control levels at a GH concentration of $1 \mathrm{ng} / \mathrm{ml}$,

251 whereas HSL1 mRNA expression was significantly increased over control levels at $10 \mathrm{ng} / \mathrm{ml} \mathrm{GH}$.

252 Significant differential expression of HSL mRNAs, with HSL2 being expressed to a greater

253 extent than HSL1, was evident in cells from fasted fish treated with $100 \mathrm{ng} / \mathrm{ml}$ and $1000 \mathrm{ng} / \mathrm{ml}$

254 GH. GH had no effect on $H S L$ mRNA expression in hepatocytes from continuously fed fish at

255 any concentration of hormone tested. Taken together, these results indicate that GH stimulates

256 HSL mRNA expression in cells from fasted fish but not in cells from continuously fed fish.

258 3.2. Previous nutritional state influences the signaling pathways activated by GH

259 Activation of cell signaling pathways by GH was studied in lysates of hepatocytes

260 isolated from 4-week fasted fish and from fish fed continuously. Activated (i.e., phosphorylated)

261 forms of JAK2, STAT5, Akt, ERK, and PKC were detected in lysates of hepatocytes from all

262 treatments. The basal activation state of JAK2, STAT5, and Akt was greater in hepatocytes from 
263 fed fish than in cells from fasted fish (Fig. 3A-3C); whereas, the basal activation state of ERK 264 and PKC was greater in hepatocytes from fasted fish than in cells from fed fish (Fig. 3D \& 3E).

265 In cells from fed fish, GH significantly increased phosphorylation of JAK2, STAT5, Akt, and

266 ERK (Fig. 3A-D). GH treatment of hepatocytes from fed fish did not change the abundance of

267 phospho-PKC (Fig. 3E). In cells from 4-week fasted fish, GH significantly increased the

268 abundance of phospho-ERK and phospho-PKC (Fig. 3D \& 3E). Notably, GH increased the

269 phosphorylation of ERK in cells from fasted fish to a greater extent than in cells from fed fish

270 (Fig. 3D). GH had no effect on the activation of JAK2, STAT5, or Akt in hepatocytes from

271 fasted fish (Fig. 3A-3C). Taken together, these results indicate that nutritional state influences

272 the complement of signal pathways activated by GH. GH activates JAK2, STAT5, and ERK in

273 hepatocytes from fed fish, whereas in cells from fasted fish, GH activated PKC and ERK; ERK

274 is activated by GH to a greater extent in cells from fasted fish than in cells from continuously fed 275 fish.

\subsection{Linkage of signal pathway activation to GH-stimulated lipolysis}

278 The linkage of specific cell signaling pathways to GH-stimulated lipolysis and GH-

279 stimulated $H S L$ mRNA expression in hepatocytes isolated from 4-week fasted fish and from fish

280 fed continuously was studied using pharmacological inhibitors previously verified for use in

281 rainbow trout (cf. Bergan et al., 2013; Reindl et al., 2011). The first series of experiments

282 examined the effects of pathway blockade on lipolysis as measured by glycerol release (Fig. 4).

283 As observed above, GH (100 ng/ml) stimulated the release of glycerol over basal levels from

284 hepatocytes isolated form fasted fish but not from fish fed continuously. Pretreatment of cells

285 from fasted fish with the PKC inhibitor, chelerythrine chloride, or with the PLC inhibitor, 
U73122, completely blocked GH-stimulated lipolysis. The MEK inhibitor, U0126, partially

287 blocked GH-stimulated lipolysis in cells from fasted fish. By contrast, inhibition of JAK2 (with 288 Hex) or PI3K (with LY294002) had no effect on GH-stimulated glycerol release from

289 hepatocytes from fasted fish. Blockade of the JAK-STAT, PI3K-Akt, MEK/ERK, or PLC/PKC 290 pathways had no effect on glycerol release form hepatocytes isolated form fed fish.

291 The second series of experiments examined the effects of pathway blockade on GH292 stimulated $H S L$ mRNA expression in hepatocytes isolated from 4-week fasted fish and from fish 293 fed continuously (Fig. 5). Similar to observations made above, GH (100 ng/ml) stimulated the 294 expression of $H S L$ mRNAs in hepatocytes from fasted fish but not in cells from fed fish. In 295 hepatocytes from fasted fish, blockade of the ERK pathway with the MEK inhibitor (U0126) 296 partially inhibited expression of HSL-encoding mRNAs. When cells from fasted fish were 297 pretreated with the PLC inhibitor (U73122) or the PKC inhibitor (chelerythrine chloride), GH298 stimulated $H S L$ expression was abolished. Similar to the effects of pathways blockade on 299 glycerol release, inhibition of JAK or PI3K had no effect on GH-stimulated HSL expression in 300 hepatocytes form fasted fish. None of the pathway inhibitors affected HSL expression in cells 301 from fed fish. Taken together, these results indicate that GH-stimulated lipolysis and GH302 stimulated HSL expression are inhibited by blockade of the PLC/PKC and ERK pathways but not 303 by blockade of the JAK-STAT or PI3K-Akt pathways.

\section{Discussion}

The results of this study indicate that GH stimulates lipolysis as well as $H S L$ mRNA

307 expression in hepatocytes from fasted fish but not in hepatocytes from fish fed continuously. In 308 addition, the effects of GH on lipolysis and HSL expression are mediated through the PLC/PKC 
and MEK-ERK signaling pathways, pathways that are not activated by GH in cells from fed fish.

310 These findings support our starting hypothesis that nutritional state modulates the lipolytic

311 responsiveness of cells by adjusting the signal transduction pathways to which GH links. Such

312 findings provide new insight into the mechanisms that underlie the differential responses of cells

313 to $\mathrm{GH}$ and how those responses can be modulated in a manner adaptive to an animal's

314 physiological or developmental state.

315 The lipolytic action of GH depends on nutritional state. This conclusion is supported by

316 two current observations. First, GH stimulated the release of glycerol from hepatocytes isolated

317 from fasted fish but not from cells isolated from fish fed continuously. Second, GH stimulated

318 the expression of HSL-encoding mRNAs in hepatocytes isolated from fasted fish but not in cells

319 isolated from fish fed continuously. These findings are consistent with the lipolytic actions of

320 GH observed in the adipose tissue of mammals (Chavez et al., 2006; Gorin et al., 1990) and in

321 the liver of fish (Bergan et al., 2013; O’Connor et al., 1993) that results in elevated plasma fatty

322 acids in both groups (Fain, 1980; Sheridan, 1994). The findings contrast with observations in

323 adipocytes of seabream in which the lipolytic effects of GH appear more pronounced from fed

324 animals than from fasted animals (Albalat et al., 2005). The basis for this difference is not

325 known, but it may reflect differences in tissue, species, and/or life history. The current findings

326 also support our recent report that the lipolytic action of GH includes activation of HSL as well

327 as de novo synthesis of HSL as reflected by enhanced HSL mRNA expression (Bergan et al.,

328 2013). Trout and other teleosts possess multiple $H S L$ mRNAs (cf. Kittilson et al., 2011) and the

329 functional significance of the two isoforms is unclear. However, interestingly, the responsiveness

330 of $H S L 2$ to GH was greater than that of HSL1 in cells from fasted fish. Structural differences in

331 the intracellular domains of the trout HSLs, including the number of potential phosphorylation 
332 sites (cf. Kittilson et al., 2011), may explain the observed differences in responsiveness to GH 333 and contribute to distinct physiological roles. Sheridan (1994) noted that GH is not universally

334 lipolytic and attributed the variability to route/duration of exposure, species/life history pattern, 335 seasonal and other rhythmicity, and interaction with other factors. For example, GH has been 336 shown to have short-term antilipolytic effects in mammalian adipose tissue not previously 337 exposed to GH (i.e., from hypophysectomized animals or from cell of normal animals 338 preincubated in the absence of $\mathrm{GH}$ ); however, the physiological relevance of such findings are 339 unclear (Carrel and Allen, 2000). In fish, chronic GH exposure was strongly lipolytic in coho 340 salmon parr; however, following smoltification, fish were refractory to GH treatment and no 341 lipolytic effects were observed (Sheridan, 1986).

342 The lipolytic action of GH in the fasting state results from selective activation of the $343 \mathrm{PLC} / \mathrm{PKC}$ and MEK/ERK signaling pathways. This conclusion is supported by several lines of 344 evidence. First, GH increased the abundance of phospho-ERK as well as of phospho-PKC in 345 cells from fish fasted 4 weeks; ERK and PKC were not activated by GH in cells from 346 continuously fed fish. Second, specific blockade of the ERK pathway or of PLC/PKC inhibited

347 GH-stimulated lipolysis as well as GH-stimulated $H S L$ expression in cells from fasted fish.

348 Third, previous work showed that fasting of rainbow trout resulted in the activation of the PKC 349 and ERK pathways accompanied by enhanced HSL activity and enhanced expression of HSL 350 mRNAs (Bergan et al., 2012). Enhanced ERK activation also has been observed in calorie351 restricted mammals (Nadeau et al., 2006). Fourth, previous work on hepatocytes from short352 term (7 day) fasted trout demonstrated that PKC and ERK mediated GH-stimulated lipolysis

353 (Bergan et al., 2013). PKC also was shown to mediate GH-stimulated lipolysis in adipose tissue 354 from rats (Gorin et al., 1990) but not in the 3T3-L1 immortal cell line stably transfected with 
hGHR (Asada et al., 2000). Lastly, crosstalk between pathways also exists, and evidence in

356 mammalian adipose indicates that PKC can activate ERK as well as PKA (Fricke et al., 2004).

357 The JAK/STAT and PI3K/Akt pathways do not play a role in GH-stimulated lipolysis.

358 This conclusion is supported by the current observation that GH increased the abundance of

359 phospho-JAK2, phospho-STAT5, and phospho-Akt in hepatocytes not undergoing lipolysis from

360 fish fed continuously; whereas, GH had no effect on the activation of JAK2, STAT5, or Akt in

361 cells undergoing lipolysis that were isolated from fasted animals. In addition, specific inhibition

362 of JAK2, PI3K, or of Akt directly had no effect on GH-stimulated lipolysis in cells from fasted

363 fish (current data; Bergan et al., 2013). Moreover, the basal phosphorylation state of JAK,

364 STAT, and Akt was lower in cells from fasted fish compared to cells from continuously feed

365 fish, an observation that was consistent with our previous study that showed that the JAK-STAT

366 and PI3K-Akt pathways were activated in tissues of fed fish that were actively growing and

367 deactivated in tissues of fasted fish that were growth retarded (Bergan et al., 2012). Fasting also

368 was shown to blunt activation of JAK-STAT in mammalian adipose and muscle tissues (Moller

369 et al., 2009).

$370 \quad$ Several possible linkages between signaling pathways and specific lipolytic responses

371 exist. Given that HSL possesses two catalytic states governed by phosphorylation sites

372 (Sheridan, 1994; Watt and Steinberg, 2008), one possible mechanism is direct activation of HSL.

373 The findings that GH-stimulated lipolysis in hepatocytes from fasted fish is dependent on ERK

374 and PLC/PKC activation coupled with our previous findings that GH-stimulated phosphorylation

375 of HSL is mediated by ERK and PLC/PKC (Bergan et al., 2013) indicate that HSL of trout is

376 activated by ERK and PLC/PKC. Studies in mammals have shown that ERK is an immediate

377 activator of HSL (Greenberg et al., 2001). Evidence shows that other kinases (e.g., cGMP- 
378 dependent protein kinases) also may activate HSL (Yeaman, 2004). Enhanced lipolysis also 379 may result from increased HSL synthesis. From early studies in rat adipocytes, GH-stimulated 380 lipolysis was found to be blocked by inhibitors of RNA and protein synthesis (Fain, 1980). The 381 present findings indicate that expression of HSL-encoding mRNAs was dependent on the ERK 382 pathway and on PKC/PLC. The $H S L$ promoter in mammals possesses several elements that may 383 be recognized by transcription factors known to associate with the PKA, PKC and ERK (SF1, 384 Sp1, C/EBPs) (Lampidonis et al., 2008; Holysz et al., 2011; Fricke et al., 2004; Piwien-Pilipuk et 385 al., 2002; Lo et al., 2007).

386 The differential activation of signal pathways observed in the present study helps resolve 387 the metabolically disparate growth-promoting and lipid catabolic actions of GH (Fig 6). During 388 periods of feeding, GH activates the JAK-STAT, PI3K/Akt, and ERK pathways (current data), 389 which in turn, leads to the synthesis and release of IGF-1 (Reindl et al., 2011; Reindl and 390 Sheridan, 2012). There is concomitant repression of catabolic pathways through 1) 391 suppression/deactivation of catabolic signaling molecules such as PKC (current data; Bergan et 392 al., 2012) and 2) Akt-mediated activation of PDE, which in turn hydrolyzes cAMP (Chavez et 393 al., 2006), thereby reducing HSL activation through PKA (cf. Bergan et al., 2013). During 394 periods when food is not available, animals cease growing and begin to mobilize stored energy 395 reserves, including a marked breakdown of stored lipids that is accompanied by an increase in 396 the activity and synthesis of HSL (Bergan et al., 2012; Han et al., 2011; Kittilson et al., 2011; 397 Mommsen and Sheridan, 1991; Norbeck et al., 2007; Tian et al., 2013). Despite the cessation of 398 growth, plasma levels of GH increase during periods of fasting in fish and other animals 399 (Gomez-Requeni et al., 2005; Norbeck et al., 2007). During this period, GH activates PLC/PKC 400 and ERK (current data), which in turn leads to the activation and synthesis of HSL (Bergan et al., 

2013). There also is a suppression/deactivation of anabolic signaling molecules such as JAK2,

402 STAT5, and Akt (current data; Bergan et al., 2012). Taken together, these findings indicate that 403 the nutritional environment governs the signal pathways to which GH links and that such linkage 404 determines whether the growth-promoting or lipid catabolic actions of GH prevail. That ERK is 405 activated by $\mathrm{GH}$ under both anabolic and catabolic conditions (but to a greater extent under 406 catabolic conditions; current data) suggests that the entire complement of signal pathways 407 activated under a given condition may be more important in determining a physiological 408 response than the activation of a specific pathway, possibly due to alterations in the network of 409 downstream events that link pathways to responses.

410 The proximate "governor" of GH-signal pathway selection is not known. There is 411 evidence that SOCS, which has been shown to selectively inhibit JAK, may play a role (Leung et 412 al., 2004). Given our postulated position of Akt at the nexus of anti-lipolysis/lipogenesis and 413 lipolysis (cf. Fig. 6), the presence (or absence) of factors that influence Akt activation, such as 414 INS and IGF-1 (Caruso and Sheridan, 2011), also may play a role. It is possible to envision, 415 therefore, that under nutrient-limiting conditions that the observed deficiency of INS and IGF-1 416 (cf. Norbeck et al., 2007) and, consequently, reduced phospho-Akt abundance, shifts the balance 417 toward GH-stimulated lipolysis; whereas, under positive nutrient conditions, the presence of INS 418 and IGF-1 and, consequently, increased abundance of phospho-Akt, the balance is shifted toward 419 the anabolism, including, possibly, the insulin-like anti-lipolytic (Carrel and Allen, 2000) actions 420 of GH. Support for such a scenario requires future work aimed at addressing the effects of INS 421 and IGFs on GH-signal pathways linkages.

422 In summary, we found that nutritional state modulates the lipolytic actions of GH. GH 423 stimulated lipolysis in hepatocytes removed from fasted rainbow trout but not in cells removed 
424 from fish that were continuously fed. The lipolytic actions of GH include activation of lipolysis

425 as measured by glycerol release as well as increased expression of HSL-encoding mRNAs.

426 During fasting GH activates the PLC/PKC and ERK pathways resulting in lipolysis, but during

427 periods of feeding GH activates a different complement of signal pathways (JAK-STAT,

$428 \mathrm{PI} 3 \mathrm{~K} / \mathrm{Akt}$, ERK) that do not promote lipolysis. These findings demonstrate that nutritional state

429 modulates the lipolytic responsiveness of cells by adjusting the cell signaling pathways to which

430 GH links and suggest possible mechanisms that underlie the disparate growth-promoting and

431 lipid catabolic actions of GH (cf. Fig. 6). On a more general level, the notion of specific GH-

432 signal pathways linkages provides insight into the potential mechanisms that underlie the

433 differential responses of cells to GH on two levels. First, cell-specific GH-signal pathway linages

434 may underlie the vast array of GH actions observed in animals (e.g., feeding, feeding, growth,

435 metabolism, osmoregulation, immune function, and behavior; cf. Bjornsson et al., 2004; Moller

436 and Jorgensen, 2009; Norrelund, 2005; Reindl and Sheridan, 2012). Second, alterations in GH-

437 signal pathway linkages provide a means for cells to adjust, either short term or long term, their

438 responsiveness to GH in a manner adaptive to an animal's physiological or developmental state.

\section{Acknowledgements}

441 We would like to thank Elle Kvam, Chad Walock, Dillon Marquart, Alicia Ickstadt,

442 Lindsey Norbeck, Andrea Hanson, Lincoln Martin, and Elizabeth Ellens, for their assistance. We

443 also thank Prof. Akiyosi Takahasi and Dr. Shiunsuke Moriyama for generously providing

444 salmonid GH. This work was supported by National Science Foundation grant IOS 0920116 to

445 M.A. Sheridan; H.E. Sheridan was supported by a ND EPSCoR fellowship funded by NSF

446 (EPS0814442). 


\section{References}

Albalat, A., Gomez-Requeni, P., Rojas, P., Medale, F., Kaushik, Vianen, G.J., Van den Thillart, G., Gutiérrez, J., Perez-Sanchez, J., Navarro, I. 2005. Nutritional and hormonal control of lipolysis in isolated gilthead sea bream (Sparus aurata) adipocytes. Am. J. Physiol. 289, R259-R265.

Asada, N., Takahashi, Y., Wada, M., Naito, H., Uchida, M., Ikeda, M., Honjo, M. 2000. GH induced lipolysis stimulation in 3T3-L1 adipocytes stably expressing hGHR: analysis on signaling pathways activity of 20K hGH. Mol. Cell. Endocrinol. 162, 121-129.

Bergan, H.E., Kittilson, J.D., Sheridan, M.A. 2012. Nutrition-regulated lipolysis in rainbow trout (Oncorhynchus mykiss) is associated with alteration in the ERK, PI3K-Akt, JAKSTAT, and PKC signaling pathways. Gen. Comp. Endcrinol. 176, 367-376.

Bergan, H.E., Kittilson, J.D., Sheridan, M.A. 2013. PKC and ERK mediate GH-stimulated lipolysis. J. Mol. Endocrinol. 51, 213-224.

Biga, P.R., Meyer, J. 2009. Growth hormone differentially regulates growth and growth-related gene expression in closely related fish species. Comp. Biochem. Physiol. A. 154, 465473.

Bjornsson, B.T., Johansson, V., Benedet, S., Einarsdottir, I.E., Hildahl, J., Agustsson, T., Jonsson, E. 2004. Growth hormone endocrinology of salmonids: regulatory mechanisms and mode of action. Fish Physiol. Biochem. 27, 227-242.

Butler, A.A., LeRoith, D.L. 2001. Control of growth by the somatotropic axis: growth hormone and the insulin-like growth factors have related and independent roles. Ann. Rev. Physiol. 63, 141-164. 
Carrel, A.L., Allen, D.B. 2000. Effects of growth hormone on adipose tissue. J. Pediatr. Endocrinol. Metab. 13, 1003-1009.

471 Caruso, M.A., Sheridan, M.A. 2011. New insights into the signaling system and function of 472 insulin in fish. Gen. Comp. Endocrinol. 173, 227-247.

473 Chavez J.,A., Gridley, S., Sano, H., Lane, W.S., Lienhard, G.E. 2006. The 47 kDa Akt substrate 474 associates with phosphodiesterase 3B and regulates its level in adipocytes. Biochem. 475 Biophys. Res. Commun. 324, 1218-1222.

476 Fain, J.N. 1980. Hormonal regulation of lipid mobilization from adipose tissue. In: Litwack, G.

477 (Ed.), Biochemical Action of Hormones, Vol 3. Academic Press, New York, pp. 119478203.

479 Fricke, K., Heitland, A., Maronde, E. 2004. Cooperative activation of lipolysis by protein kinase 480 A and protein kinase C pathways in 3T3-L1 adipocytes. Endocrinology 145, 4940-4947.

481 Gomez-Requeni, P., Calduch-Giner, J., Vega-Rubin de Celis, S., Medale, F., Kaushik, S.J., Prez482 Sanchez, J. 2005. Regulation of the somatotropic axis by dietary factors in rainbow trout

484 Gorin, E., Tai, L., Honeyman, T.W., Goodman, H.M. 1990. Evidence for a role of protein kinase 485 (Oncorhynchus mykiss). Brit. J. Nutr. 94, 353-361.

487 Greenberg, A.S., Shen, W.J., Muliro, K., Patel, S., Souza, S.C., Roth, R.A., Kraemer, F.B. 2001. 488 Stimulation of lipolysis and hormone-sensitive lipase via the extracellular signalregulated kinase pathway. J. Biol. Chem. 276, 45456-45461. 
Han, C., Wen, X., Zheng, Q., Li, H. 2011. Effect of starvation on activities and mRNA expression of lipoprotein lipase and hormone-sensitive lipase in tilapia (Oreochromis niloticus x O. areus). Fish Physiol. Biochem. 37, 113-122.

Holsyz, M., Derebecka-Holszy, N., Trzeciak W.H. 2011. Transcription of LIPE gene encoding hormone-sensitive lipase/cholesteryl esterase is regulated by SF-1 in human adrenocortical cells: involvement of protein kinase A signal transduction pathway. J. Mol. Endocrinol. 46, 29-36.

Kittilson, J.D., Reindl, K.M., Sheridan, M.A. 2011. Rainbow trout (Oncorhynchus mykiss) possess two hormone-sensitive lipase-encoding mRNAs that are differentially expressed and independently regulated by nutritional state. Comp. Biochem. Physiol. A 158, 52-60.

Lampidonis, A.D., Stravopodis, D.J., Voutsinas, G.E., Messini-Nikolaki, N., Stefos, G.C., Margaritis, L.H., Argyrokastritis, A., Bizelis, I., Rogdakis, E. 2008. Cloning and functional characterization of the 5' regulatory region of ovine hormone sensitive lipase (HSL) gene. Gene 427, 65-79.

Leung, K., Johannsson, G., Leong, G.M., Ho, K.K.Y. 2004. Estrogen regulation of growth hormone action. Endocr. Rev. 25, 693-721.

Lo, J.H., Chiou, P.P., Lin, C.M., Chen, T.T. 2007. Molecular cloning and expression analysis of rainbow trout (Oncorhynchus mykiss) CCAAT/enhancer binding protein genes and their response to induction by GH in vitro and in vivo. J. Endocrinol. 194, 393-406.

Moller, N., Jorgensen, J.O.L. 2009. Effects of growth hormone on glucose, lipid, and protein metabolism in human subjects. Endocr. Rev. 30, 152-177. 
511 Moller, L., Dalman, L., Norrelund, H., Billestrup, N., Frystyk, J., Moller, N., Jorgensen, J.O.L.

512 2009. Impact of Fasting on Growth Hormone Signaling and Action in Muscle and Fat. J.

513 Clin. Endocrinol Metab. 94, 965-972.

514 Mommsen, T.P., Moon, T.W., Walsh, P.J. 1994. Hepatocytes: isolation, maintenance, and utilization. In: Hochachka, P.W., Mommsen, T.P. (Eds.), Biochemistry and Molecular Biology of Fish. Elsevier, New York, pp. 355-373.

Nadeau, K.J., Ehlers, L.B., Aguirre, L.E., Moore, R.L., Jew, K.N., Ortmeyer, H.K., Hansen, B.C., Reusch, J.E.B., Draznin, B. 2006. Exercise training and caloric restriction increases SREBP-1 expression and intramuscular triglyceride in skeletal muscle. Am. J. Physiol. 291, E90-E98.

Norbeck, L.A., Kittilson, J.D., Sheridan, M.A. 2007. Resolving the growth-promoting and metabolic effects of growth hormone: differential regulation of GH-IGF-I system components. Gen. Comp. Endocrinol. 151, 332-341.

524 Norrelund, H. 2005. The metabolic role of growth hormone in humans with particular reference to fasting. Growth Horm. IGF Res. 15, 95-122.

526 O’Connor, P.K., Reich, B., Sheridan, M.A. 1993. Growth hormone stimulates hepatic lipid mobilization in rainbow trout, Oncorhynchus mykiss. J. Comp. Physiol. B 163, 427-431.

528 Piwien-Pilipuk, G., Huo, J.S., Schwatz, J. 2002. Growth hormone signal transduction. J. Pediatr. Endocrinol. Metab. 15, 771-786.

Reindl, K.M., Kittilson, J.D., Bergan, H.E., Sheridan, M.A. 2011. Growth hormone-stimulated insulin-like growth factor-1 expression in rainbow trout (Oncorhynchus mykiss) hepatocytes is mediated by ERK, PI3K-AKT, and JAK-STAT. Am. J. Physiol. 301, R236-R243. 
534 Reindl, K.M., Sheridan, M.A. 2012. Peripheral regulation of the growth hormone-insulin-like growth factor system in fish and other vertebrates. Comp. Biochem. Physiol. A 163, 231245.

537

Reinecke, M., Bjornsson, B.Th., Dickhoff, W.W., McCormick, S.D., Navarro, I., Power, D.M., Gutierrez, J. 2005. Growth hormone and insulin-like growth factors in fish: where we are and where to go. Gen. Comp. Endocrinol. 142, 20-24.

Sheridan, M.A. 1986. Effects of thyroxin, cortisol, growth hormone, and prolactin on lipid metabolism of coho salmon, Oncorhynchus kisutch, during smoltification. Gen. Comp. Endocrinol. 64, 220-238.

Sheridan, M.A. 1994. Regulation of lipid metabolism in poikilothermic vertebrates. Comp. Physiol. Biochem. B 107, 495-508.

Sheridan, M.A., Mommsen, T.P. 1991. Effects of nutritional state on in vivo lipid and carbohydrate metabolism of coho salmon, Oncorhynchus kisutch. Gen. Comp. Endocrinol. 81, 473-483.

Tian, J., Wen, H., Zeng, L., Jiang, M., Wu, F., Liu, W., Yang, C. 2013. Changes in the activities and mRNA expression levels of lipoprotein lipase (LPL), hormone-sensitive lipase (HSL) and fatty acid synthetase (FAS) of Nile tilapia (Oreochromis niloticus) during fasting and re-feeding. Aquaculture 400, 29-35.

Watt, M.J., Steinberg, G.R. 2008. Regulation and function of triacylglycerol lipases in cellular metabolism. Biochem. J. 414, 313-325.

Won, E.T., Borski, R.J. 2013. Endocrine regulation of compensatory growth in fish. Front. Endocrinol. 4(74), 1-13.

Wood, A.W., Duan, C., Bern, H.A. 2005. Insulin-like growth factor signaling in fish. Int. 
558 Yeaman, S.J. 2004. Hormone-sensitive lipase — new roles for an old enzyme. Biochem. J. 379, $559 \quad 11-22$ 


\section{Legends to Figures}

561 Fig. 1. Growth hormone (GH)-stimulated lipolysis as measured by glycerol release from

Fig. 3. Effects of growth hormone $(\mathrm{GH})$ on the abundance of phosphorylated Janus kinase 2 (JAK2), signal transducer and activator of transcription 5 (STAT5), protein kinase B (Akt), extracellular signal-regulated kinase (ERK), and protein kinase $\mathrm{C}(\mathrm{PKC})$ in 
isolated hepatocytes of rainbow trout fed continuously or fasted for 4 weeks. Cells were incubated in the absence or presence of $100 \mathrm{ng} / \mathrm{ml}$ of $\mathrm{GH}$ for $30 \mathrm{~min}$. Data are presented as $\%$ of control (cells from fed animals treated with $0 \mathrm{ng} / \mathrm{ml} \mathrm{GH}$ ) are expressed as means \pm S.EM. $(n=4)$. Groups with different letters are significantly $(\mathrm{p}<0.05)$ different.

Fig. 4. Effects of signaling element blockade on growth hormone (GH)-stimulated lipolysis as measured by glycerol release from hepatocytes isolated from rainbow trout fed

Fig. 5. Effects of signaling element blockade on growth hormone (GH)-stimulated expression of (fed or fasted), groups with different letters are significantly $(\mathrm{p}<0.05)$ different; * indicates significant difference between nutritional states within the same treatment. continuously or fasted for 4 weeks. Cells were pretreated for $2 \mathrm{~h}$ with or without specific inhibitors for the following signaling elements: MEK (10 $\mu \mathrm{M} \mathrm{U0126),} \mathrm{PI3K} \mathrm{(10} \mu \mathrm{M}$ LY294002), JAK (10 $\mu$ M Hex.), PKC (10 $\mu \mathrm{M}$ chelerythrine chloride), PLC (10 $\mu \mathrm{M}$ U73122); after which time, cells were treated with $100 \mathrm{ng} / \mathrm{ml} \mathrm{GH}$ for $6 \mathrm{~h}$ (control is 0 ng/ml GH). Data are presented as means \pm S.E.M. $(n=6)$. For a given nutritional state hormone sensitive lipase (HSL) 1- and HSL2-encoding mRNAs in hepatocytes isolated from rainbow trout fed continuously (A) or fasted for 4 weeks (B). Cells were pretreated for $2 \mathrm{~h}$ with or without specific inhibitors for the following signaling elements: MEK (10 $\mu \mathrm{M}$ U0126), PI3K (10 $\mu \mathrm{M}$ LY294002), JAK (10 $\mu \mathrm{M}$ Hex.), PKC (10 $\mu$ M chelerythrine chloride), PLC (10 $\mu \mathrm{M}$ U73122); after which time, cells were treated with $100 \mathrm{ng} / \mathrm{ml} \mathrm{GH}$ for $6 \mathrm{~h}$. Data are presented as $\%$ of control $(0 \mathrm{ng} / \mathrm{ml} \mathrm{GH})$ and expressed as mean $\pm \mathrm{SEM}$ $(n=6)$. For a given HSL isoform, groups with different letters are significantly $(p<0.05)$ different. * indicates significant difference between HSL isoforms within the same treatment. 
Fig. 6. Model of the modulation of growth hormone $(\mathrm{GH})$-signal pathway linkages and the activation of growth-promoting or lipid mobilizing (lipolysis) responses by nutritional state. When animals are in an anabolic state (e.g., during periods of feeding), GH initially activates JAK2 which, in turn, activate Raf-MEK-ERK, PI3K-Akt, and STAT5. Crosstalk between the PI3K-Akt and Raf-MEK-ERK pathways exists via Akt activation of Raf. ERK, Akt, and STAT5 all promote growth via the synthesis and secretion of IGF-1. Lipolysis is retarded in the anabolic state as a result of Akt activation of PDE and the ensuing degradation of cAMP, a factor involved in activation of the lipolytic enzyme, hormone sensitive lipase (HSL), concomitant with repression of activation of catabolic signal elements (PLC/PKC). When animals are in a catabolic state (e.g., during periods of fasting), PLC and PKC are activated, which are essential for propagation of signal to activate Ras/GRP-MEK-ERK and, possibly, PKA (not shown). Lipolytic processes involve activation (via phosphorylation) of HSL, which hydrolyzes stored triacylglycerol to fatty acids and glycerol, as well as de novo synthesis of HSL as reflected by increases in HSL mRNA expression. HSL can be directly activated by PKA, PKC, and ERK. Expression of HSL mRNAs is enhanced by PKC, ERK, and PKA via a variety of transcription factors to which these signal elements interact (e.g., SF1, Sp1, C/EBPs). GH-stimulated lipolysis is accompanied by deactivation of the JAK-STAT and PI3K-Akt pathways; lower Akt abundance results in reduced activation of antilipolytic processes (via PDE) and the favoring of lipolysis. Indeterminate number steps are indicated by dashed lines. (This model represents a synthesis of many studies; see discussion for details and references.) 
A. Time

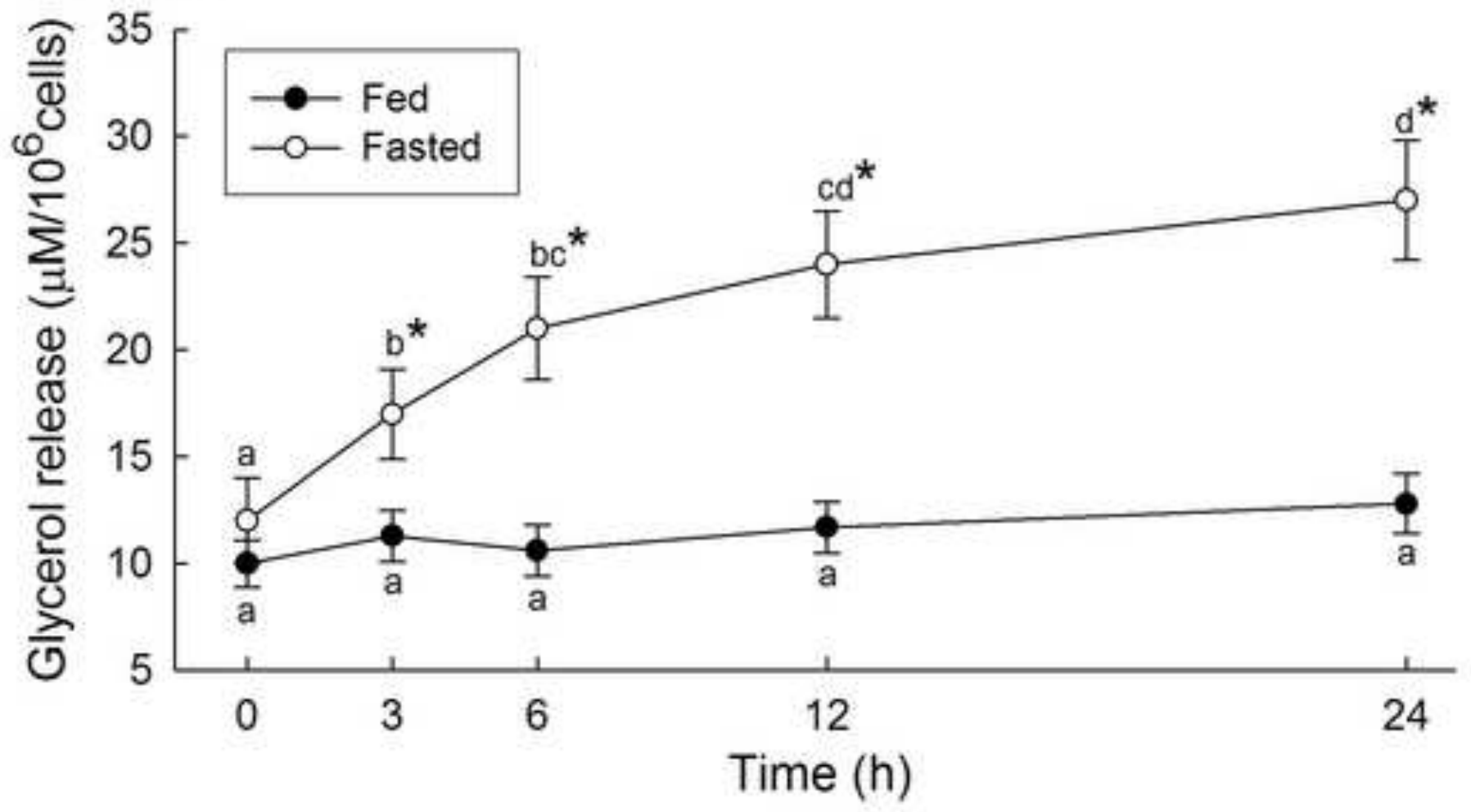

\section{B. Concentration}

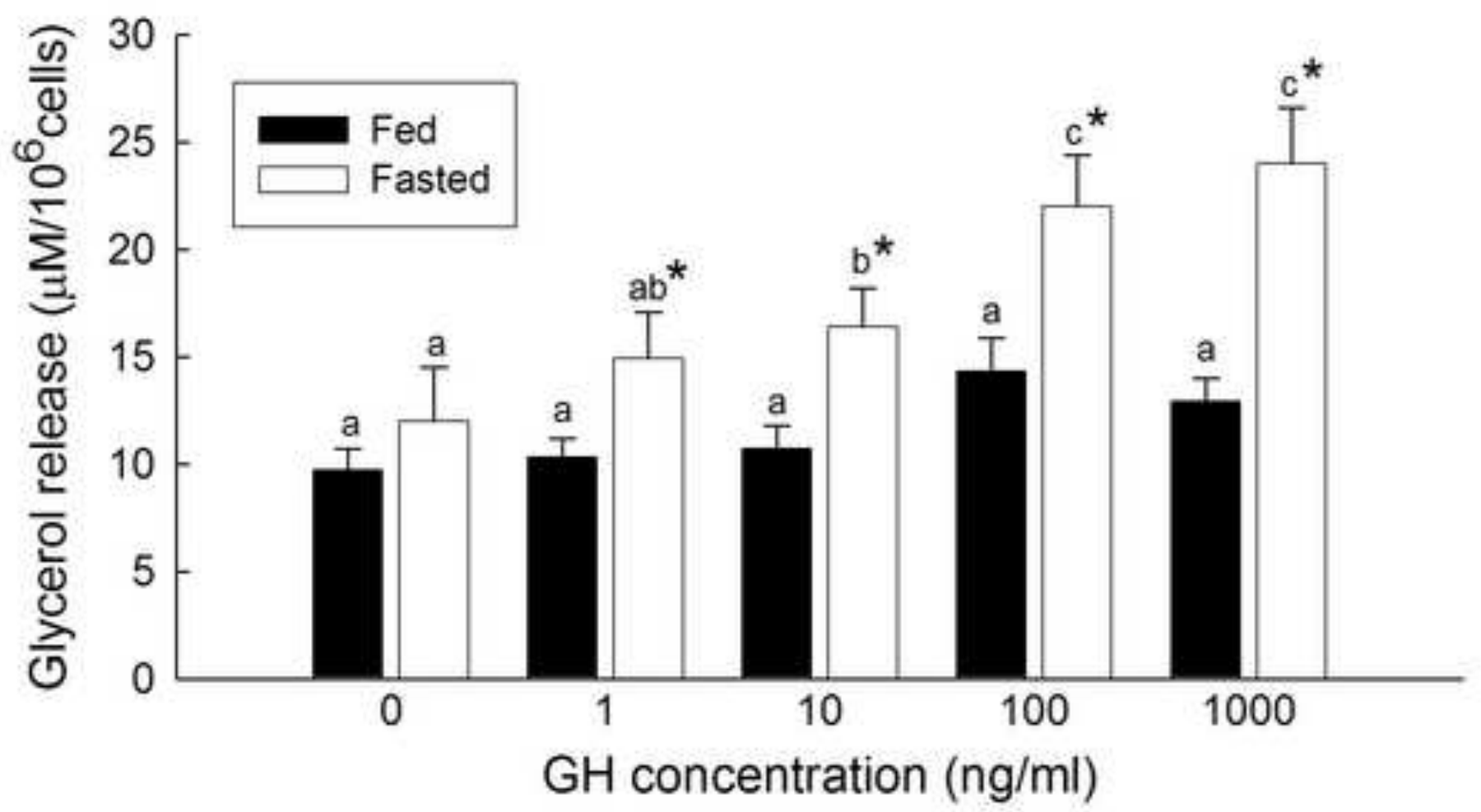



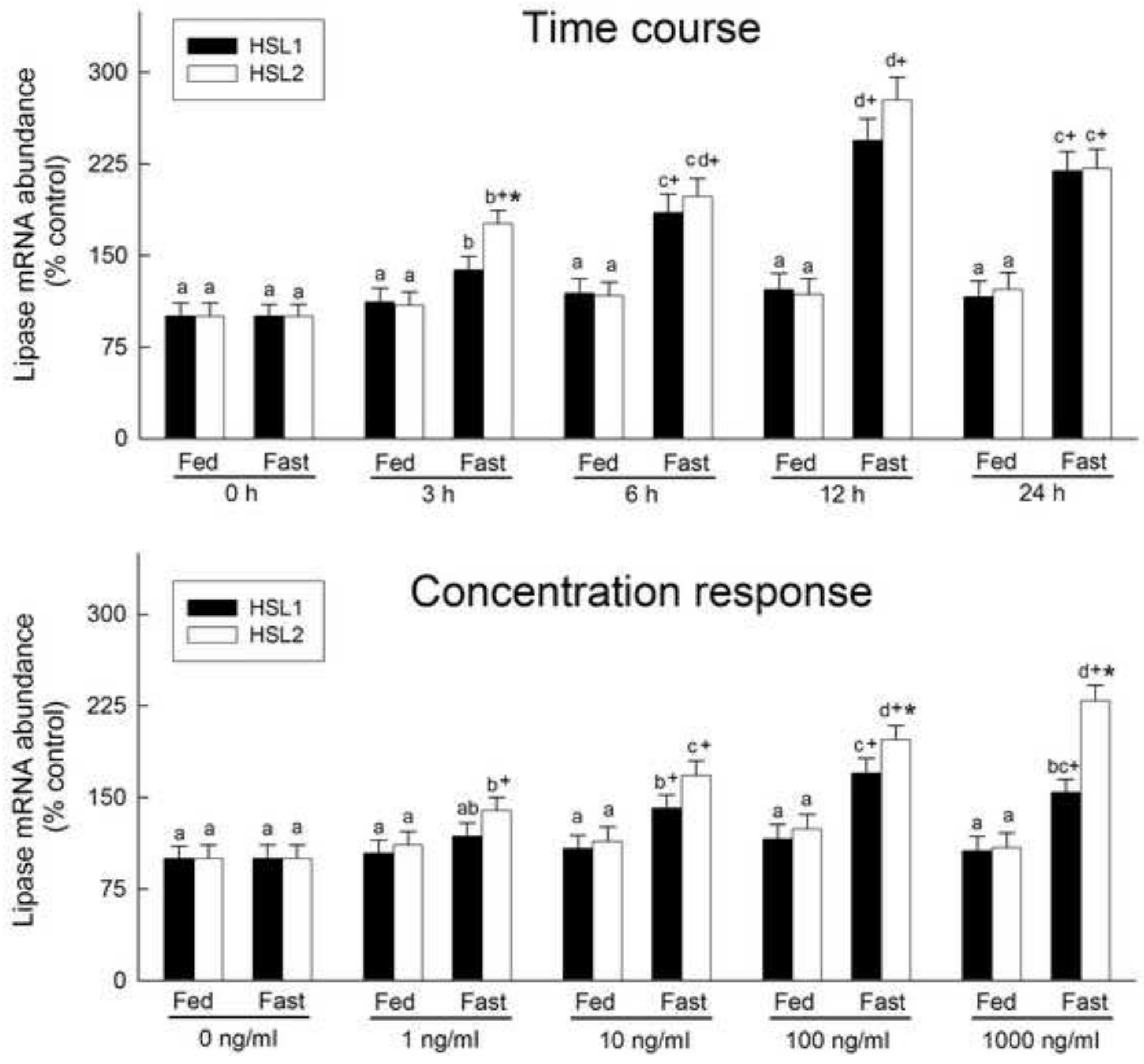
A. JAK2

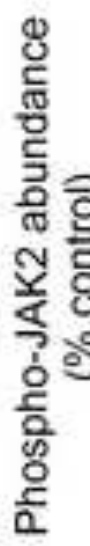

C. Akt

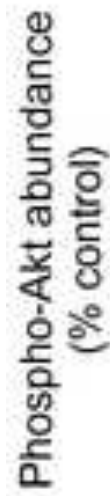
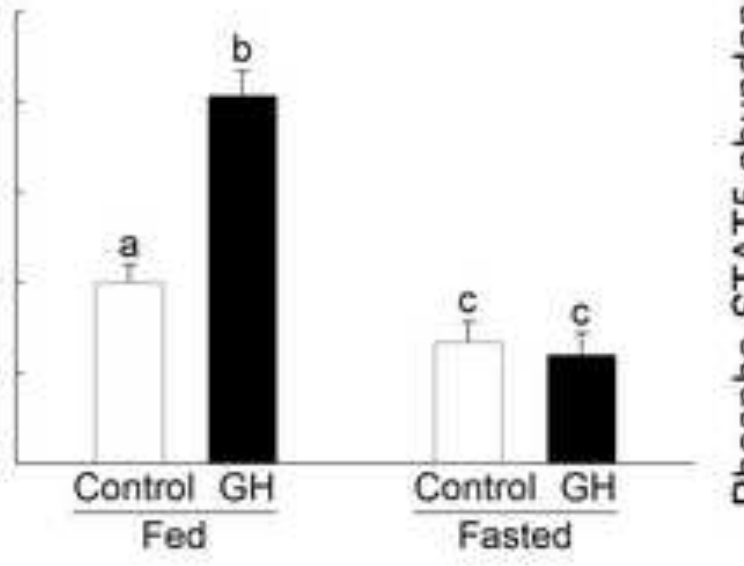

Fasted
B. STAT5

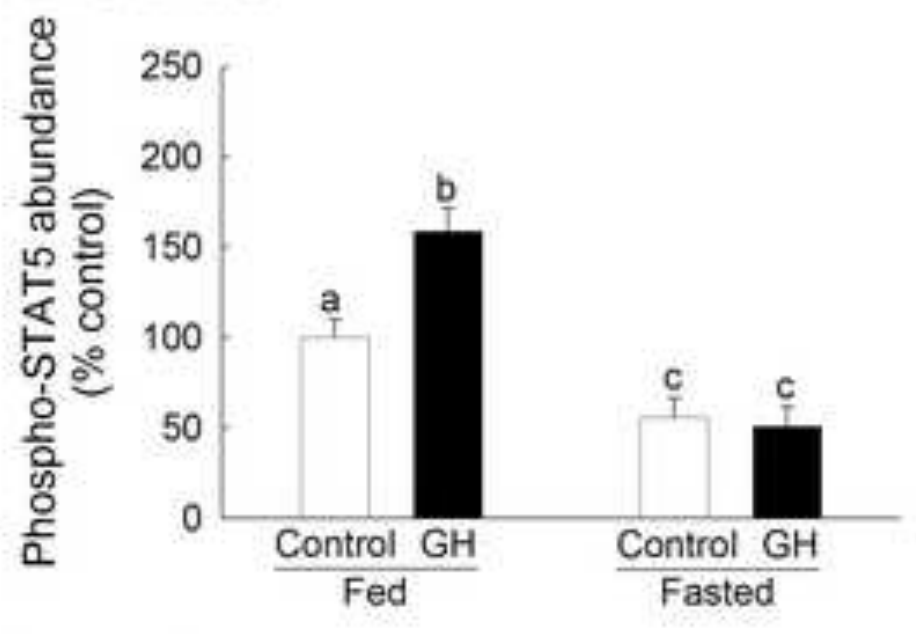

D. ERK

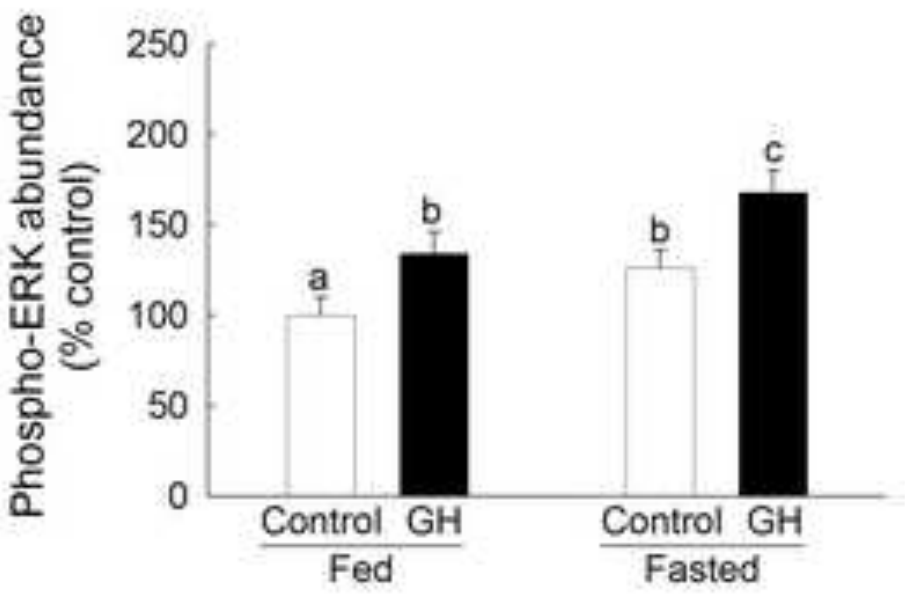

\section{E. PKC}

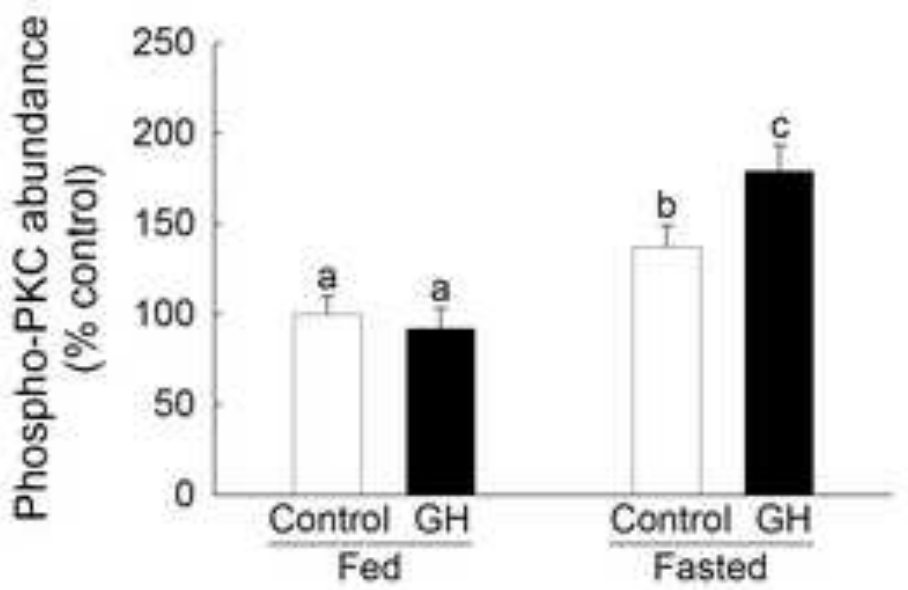




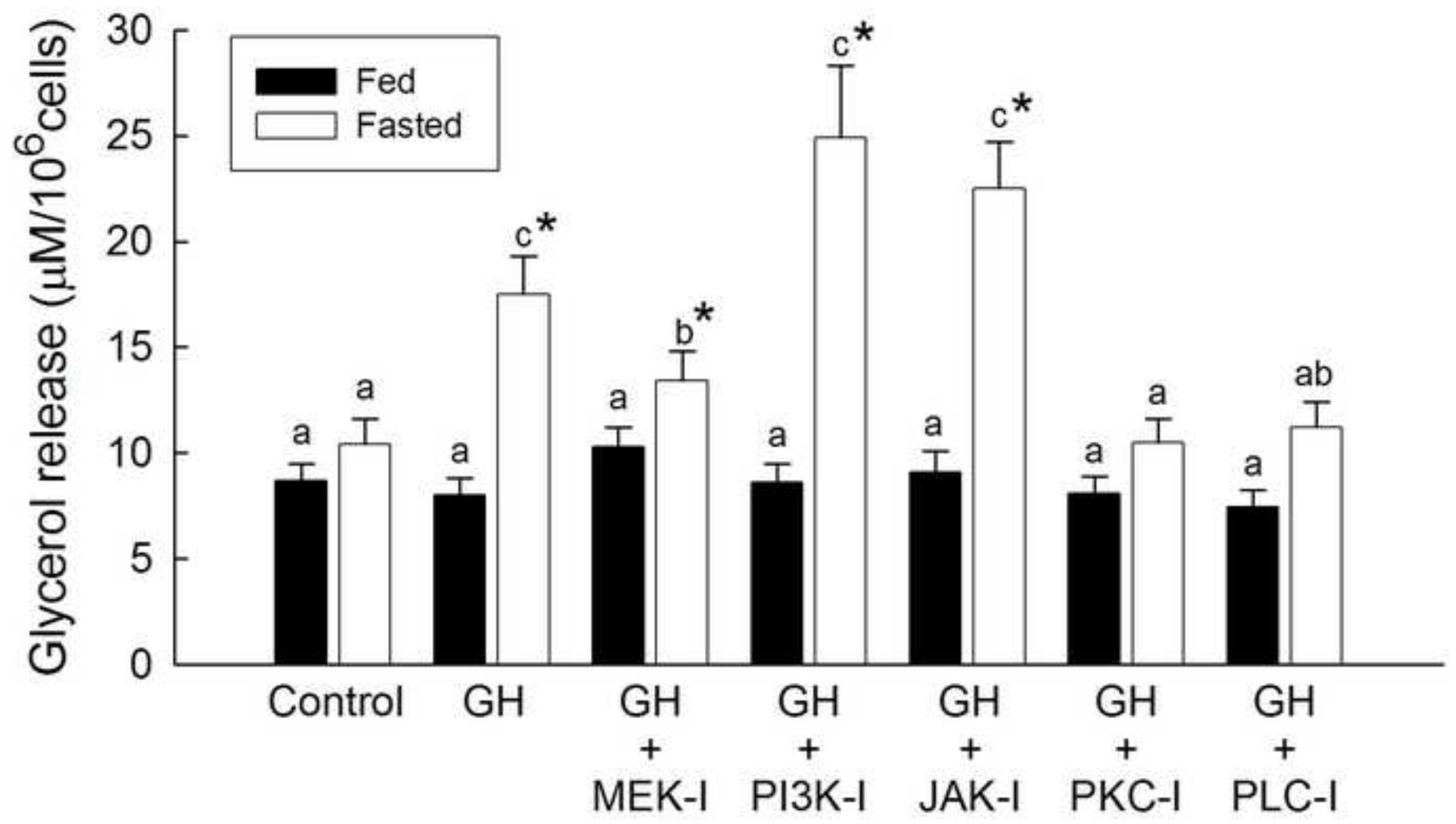



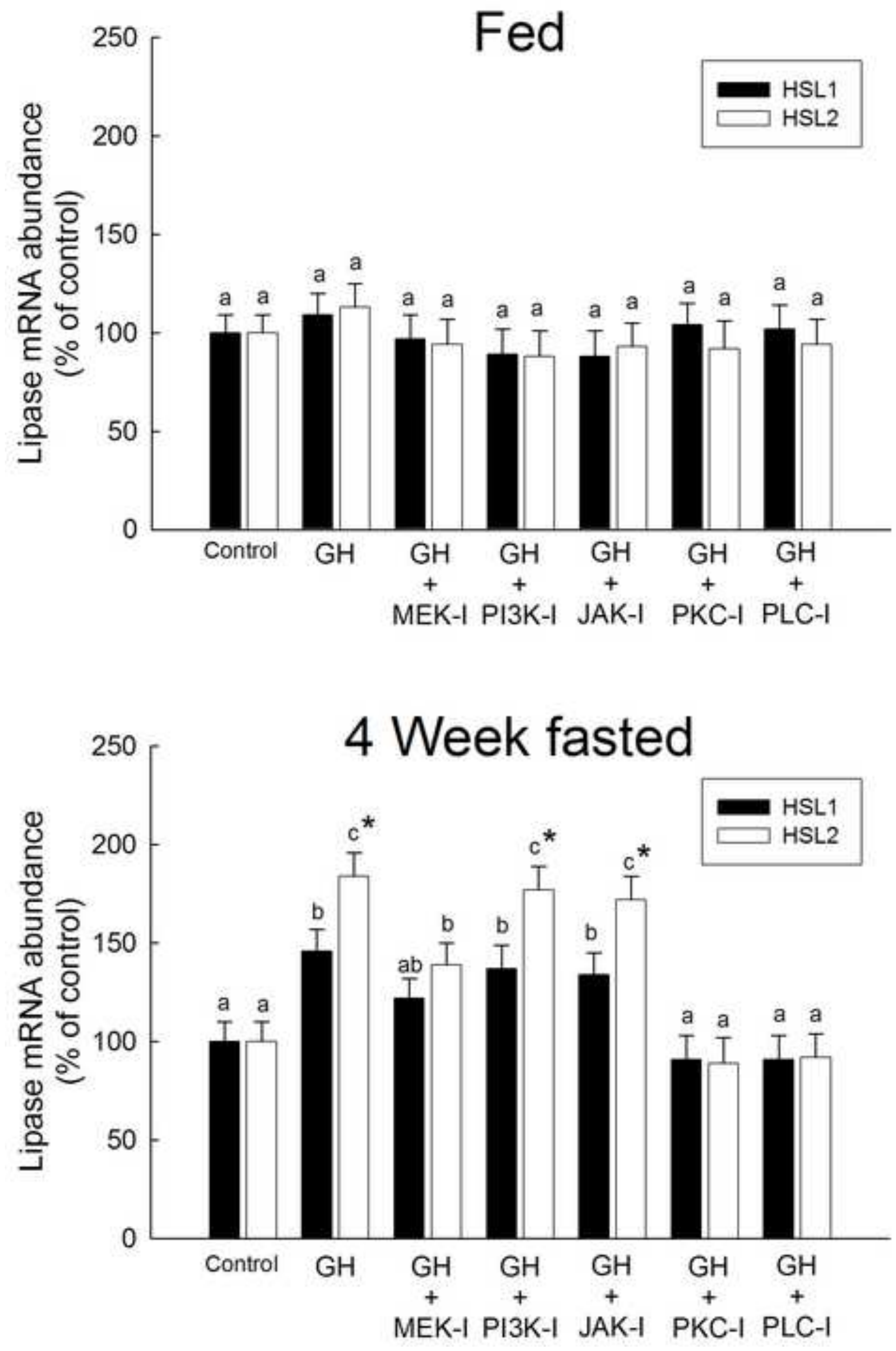


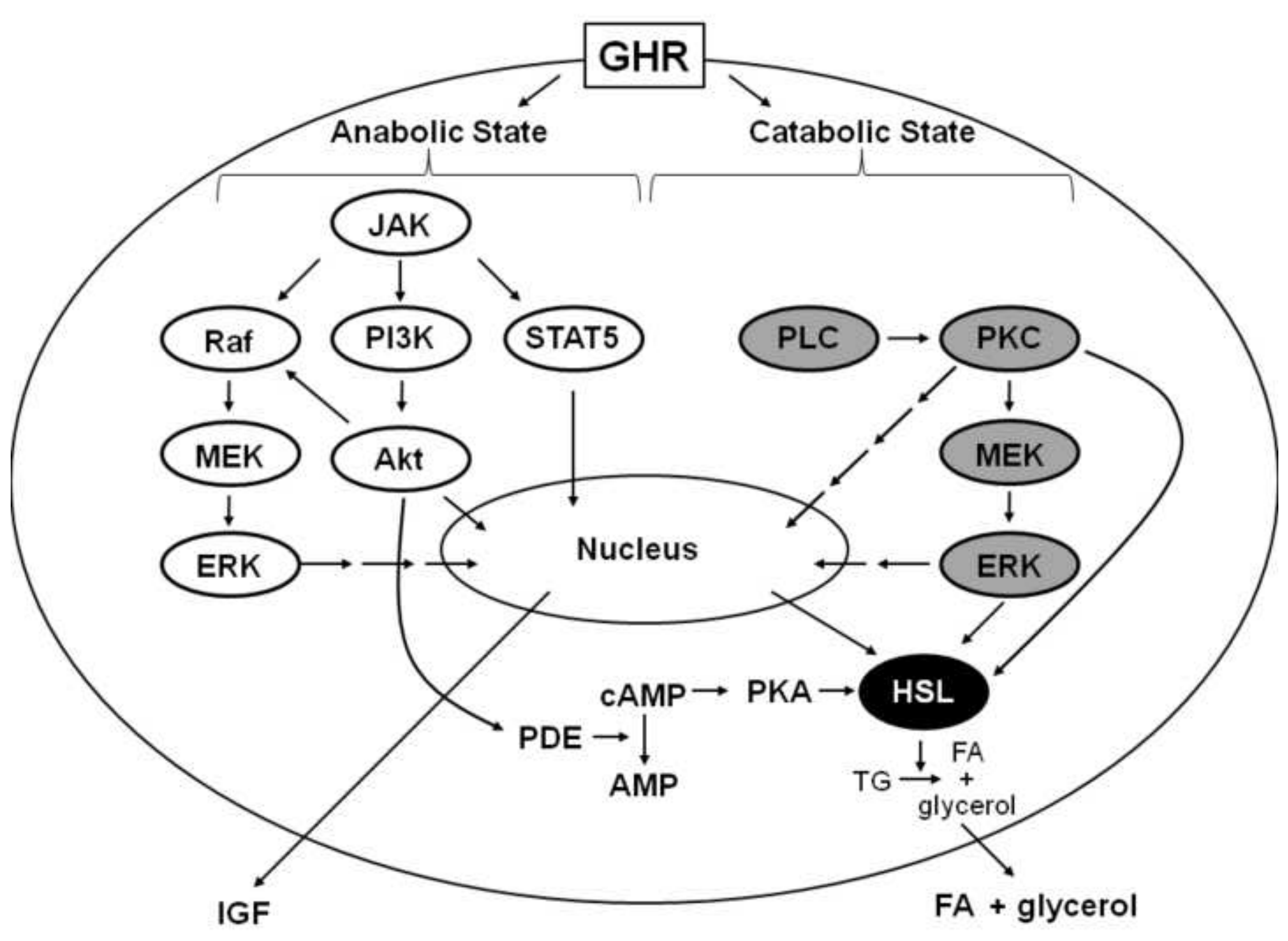

